\title{
DOSSIÊ
}

Sociologias, Porto Alegre, ano 4, no 7, jan/jun 2002, p. 18-49

\section{Construindo a possibilidade da participação dos usuários: conselhos e conferências no Sistema Único de Saúde}

ste artigo se propõe, inicialmente, a discutir algumas afirmações presentes na literatura internacional sobre a questão da participação no contexto do processo de reforma setorial em países em desenvolvimento, marcadamente no setor saúde. De acordo com os autores (Grindle e Thomas, 1991; U galde, 1985), seria muito difícil criar canais participatórios nos chamados países em desenvolvimento, em geral e na América Latina em particular, devido às características de suas instituições políticas. Supõe-se que estas seriam dominadas por pactos e acertos informais elitistas e apresentariam sociedades civis fracas (Grindle e Thomas, 1991). Na área da saúde as iniciativas para promover a participação teriam resultado em manipulação dos participantes e na destruição de formas populares de organização (U galde, 1985). A experiência brasileira, com os conselhos e as conferências de saúde, não confirma integralmente tais afirmações. Estudos revelam que, em alguns casos e em determinadas conjunturas, esses fóruns têm participado do processo decisório no setor e têm contado com a participação de representantes dos usuários de serviços de saúde (Carvalheiro e outros, 1992; Cortes, 1995, Cortes, 2000). Daí advém o questionamento sobre as origens e o papel institucional e político desses fóruns no contexto da reforma do sistema de saúde brasileiro, bem como sobre as condições que viabilizariam

* Universidade Federal do Rio Grande do Sul (UFRGS), Núcleo Interdisciplinar de Pesquisa em Saúde Coletiva (NIPESC) 
Sociologias, Porto Alegre, ano 4, № 7, jan/jun 2002, p. 18-49

o êxito de tais experiências participatórias. A segunda e terceira partes do artigo procuram responder a essas indagações.

Para que a discussão aqui promovida seja inteligível, é necessário fazer dois esclarecimentos iniciais. Em primeiro lugar, a literatura sobre 0 tema tem tratado como participantes em potencial a comunidade, o consumidor, as classes populares (participação popular), o cidadão e o usuário. A utilização de um ou outro conceito de participante depende principalmente da orientação política e ideológica de quem o empregar. Neste artigo é mais freqüente o uso do conceito participação dos usuários. Ele se refere àqueles que utilizam determinados serviços em uma dada área territorial. Embora tenha alguma similaridade com o conceito de participação do consumidor, ele não se restringe à perspectiva mercantil e incorpora a noção de direito social que o conceito de cidadania normalmente pressupõe. Além disso, desde a segunda metade da década passada, 0 termo participação do usuário tem sido o mais empregado por estudiosos do tema e pelos documentos oficiais brasileiros. Em segundo lugar, a literatura trabalha com diferentes modalidades ou gradações do que seria participação (Arnstein, 1969; Cortes, 1996(a); Ham, 1980; Lee e Mills, 1985; Paul, 1987). As formas de envolvimento dos participantes podem ser qualificadas como manipulação, consulta, negociação ou até mesmo participação. Neste artigo, considera-se que há participação quando o envolvido tomar parte no processo de decisão política (Lee e Mills, 1985; Paul, 1987).

\section{Consolidação de canais participatórios no Brasil, na área de saúde: improvável, mas possível}

Durante as duas últimas décadas, nos países desenvolvidos, a institucionalização de mecanismos participatórios tem sido vista como um complemento ou como uma alternativa às formas tradicionais de representação política nas democracias liberais. No mesmo período, as agências in- 
ternacionais têm preconizado que nos países em desenvolvimento sejam promovidas a auto-sustentação econômica e a participação comunitária, vistas como meios para atingir o desenvolvimento. O s cuidados primários de saúde seriam uma das principais estratégias para melhorar as condições de saúde nesses países. U ma de suas diretrizes centrais consiste no estímulo à participação comunitária. Tem sido questionada, no entanto, a possibilidade de serem criados mecanismos que permitam a participação dos setores populares no processo de decisão política em países em desenvolvimento e, particularmente, em países latino-americanos.

Desde os anos trinta, dirigentes políticos e acadêmicos consideravam que o Estado deveria ser o condutor do crescimento econômico e o promotor do bem estar social (Grindle e Thomas, 1991, p.2). Os governos centrais seriam os impulsionadores do progresso, particularmente, nos países em desenvolvimento. Neles, a grande distância entre os objetivos propostos e a realidade, marcada por enormes problemas sociais e econômicos, parecia justificar a defesa do planejamento e execução centralizada. Nos anos oitenta, o agravamento da crise econômica internacional e a ascensão ao poder de políticos conservadores em países centrais da economia internacional determinaram uma mudança de enfoque. 0 s dirigentes políticos desses países passaram a defender idéias inspiradas no pensamento da nova direita, influenciando as agências internacionais a proporem o "ajustamento estrutural" das economias dos países em desenvolvimento, através de políticas que reduzissem drasticamente o tamanho do aparelho estatal. As agências internacionais passaram a recomendar reformas baseadas em teorias econômicas neoclássicas, desafiando a idéia do Estado indutor do crescimento econômico e do bem estar social. Advogava-se uma maior distribuição de poder, na qual a privatização e a devolução de funções e recursos nos níveis subnacionais de governo tornaram-se noções chaves (Grindle e Thomas, 1991, p.2). A nova concepção de desenvolvimento, combinada com a idéia de cuidados primários de saúde, teve influência profunda na reforma do sistema brasileiro de saúde iniciada nos anos oitenta. 
A estratégia de cuidados primários de saúde criticava a concentração de investimentos em poucas unidades complexas de saúde, principalmente hospitais, em geral localizados em alguns centros urbanos de larga densidade populacional (W alt, 1994, p.5, 24). O s recursos deveriam ser usados racionalmente, enfatizando a aplicação de tecnologias simplificadas através de uma rede de senviços hierarquizada que cobriria toda a população, embora tivesse como alvo prioritário os setores sociais mais pobres. Nos países em desenvolvimento, a implantação de políticas inspiradas nessa estratégia freqüentemente resultaram na extensão da cobertura dos serviços de saúde a regiões rurais e a áreas urbanas que concentravam populações de baixa renda (Paim, 1989, p.19; Walt, 1994, p.5). A administração da rede de serviços deveria ser descentralizada e contaria com a participação da comunidade.

A noção de participação, tal como fora inicialmente concebida pelos defensores dos cuidados primários de saúde, era muito vaga, e seu significado variava conforme as peculiaridades da organização social e política de cada país, ou do posicionamento político-ideológico do ator político que abraçava a idéia. Segundo Grindle e Thomas (1991, p.43-69), nos países em desenvolvimento, os tipos de relações, que normalmente se estabelecem entre instituições políticas e sociedade civil, dificultariam a constituição de mecanismos participatórios. U ma das características desses países seria a fraqueza ou ausência de sociedade civil organizada capaz de contrabalançar o poder político das elites econômicas e militares em aliança com a burocracia estatal. Particularmente na América Latina, o processo de tomada de decisões políticas teria sido tradicionalmente conduzido através de canais informais, nos quais os interesses empresariais e militares estariam diretamente representados dentro da estrutura burocrática do Estado (Cardoso, 1975, p.165-86). Nos países latino-americanos os interesses não dominantes - tais como os dos sindicatos, dos trabalhadores rurais, dos moradores urbanos pobres - seriam sistematicamente excluídos dos canais decisórios. Suas demandas seriam filtradas por relações estabelecidas por funcionários públicos com líderes obsequiosos e clientes individuais. 
Embora essa caracterização seja apropriada para a maior parte da história republicana brasileira, ela é apenas parcialmente adequada para retratar a vida política brasileira, durante os anos oitenta. As prescrições das agências internacionais, defendendo a redução do papel do governo federal como provedor de bens e de serviços - e propondo a participação comunitária, dirigiam-se a um país cuja economia praticamente parara de crescer. Os anos oitenta foram conhecidos como a "década perdida", principalmente porque se caracterizaram pela combinação de altas taxas de inflação com crescimento econômico negativo ou muito baixo. 0 declínio da atividade econômica virtualmente neutralizara o governo central como agente indutor do desenvolvimento econômico. No entanto, concomitantemente, a sociedade civil demonstrava uma capacidade de organização sem precedentes, ao mesmo tempo em que se liberalizava a vida política.

No final dos anos setenta, intensificavam-se a mobilização e a organização da sociedade civil brasileira. O "novo movimento sindical" demandava ativamente aumentos salariais e liberdade de organização enquanto se opunha abertamente à ditadura militar (Almeida, 1984, p.191-214; Keck, 1989, p.252-96). Pela primeira vez, desde o começo dos anos sessenta, sindicatos de trabalhadores rurais e o movimento dos sem terra exigiam reforma agrária e a extensão de benefícios previdenciários a trabalhadores rurais (Grzybowski, 1987; Hall, 1990, p.187-232). Nas áreas urbanas, associações de moradores promoviam campanhas demandando melhores serviços ou mesmo, por vezes, ocupando conjuntos residenciais vazios e prédios públicos (Baierle, 1992; Martes, 1990). N ovas organizações sociais eram criadas, tais como associações ecológicas e grupos feministas. Esses movimentos e organizações tinham como ponto comum a oposição ao governo militar.

O clímax da liberalização política, durante os anos oitenta, deu-se com o fim da ditadura militar e a promulgação da Constituição em 1988. A Constituição instituiu "um regime competitivo liberal de oligarquias", no qual todos os brasileiros eram formalmente considerados cidadãos (W effort, 1988, p.16). Ela criou mecanismos de envolvimento das classes populares 
na administração pública - como o referendum, o plebiscito, a iniciativa popular - e estabeleceu que deveria haver participação popular, particularmente na área da saúde (M oisés, 1990, p.33; Brasil, 1988, art. 194/VII).

A organização da sociedade civil e a liberalização política ocorrida não têm sido incorporadas a muitas análises dos processos recentes de reforma social e de mudança nas instituições políticas latino-americanas. Grindle e Thomas (1991, p.63) afirmaram que na maior parte dos países em desenvolvimento grandes parcelas da população - camponeses e moradores urbanos favelados - não são organizadas de modo a sustentar atividades políticas regulares. Os interesses sociais seriam freqüentemente representados através de processos informais, ao invés de formas públicas de pressão. Esse era o caso do Brasil, particularmente durante as décadas de sessenta e setenta, quando se combinavam a ausência de democracia política e a exclusão de milhões de pessoas do acesso a bens e serviços básicos, disponíveis para outros através da rápida industrialização e modernização. Para os anos oitenta e início dos anos noventa, entretanto, essa caracterização torna-se imprecisa, na medida em que retrata apenas parcialmente a dinâmica social e política do país. Em várias cidades, especialmente na área da saúde, setores dos movimentos sociais urbano, rural e sindical mobilizavam-se e, inicialmente, apresentavam suas reivindicações diretamente a gestores e políticos. A partir da segunda metade da década de oitenta, esses movimentos passaram a canalizar suas demandas para as comissões interinstitucionais municipais de saúde, e depois, para os conselhos e as conferências de saúde. Através desses canais participatórios, eram apresentadas formal e publicamente as demandas daqueles setores sociais recorrentemente excluídos dos processos decisórios. Para que isso ocorresse, de forma sistemática e continuada, seriam necessárias algumas precondições.

Em primeiro lugar, o estabelecimento desses canais de efetiva participação, requereria a existência de organizações da sociedade civil, que pudessem sustentar e legitimar aqueles que representassem os interesses dos setores sociais que elas aglutinavam (M armor, 1983, p.92). Em segun- 
do lugar, seria necessário contar com uma policy community interessada na construção de canais participatórios. Policy community é entendida como uma comunidade orgânica de atores políticos organizados em torno de um projeto comum de política social (Jordan e Richardson, 1982, p.83). U m importante ator dessa comunidade é a elite política setorial, composta por profissionais e acadêmicos que colaboram decisivamente para a elaboração de projetos reformistas (Grindle e Thomas, 1991, p.20). No caso da reforma do sistema brasileiro de saúde, havia os ativistas dos movimentos sociais, ansiosos por influenciar a formulação e implementação das políticas do setor. Havia, também, uma elite de reformadores tentando criar alianças e coalizões para influenciar o processo de tomada de decisões dentro do governo (M elo, 1993, p.130-136).

Grindle e Thomas (1991, p.32-4) relacionaram a fraqueza dos mecanismos de representação de interesses coletivos, nos países em desenvolvimento, ao forte papel que assumiriam as elites políticas setoriais na formulação e na implementação de reformas, independente de articulações com organizações da sociedade civil. No entanto, a elite de reformadores do sistema brasileiro de saúde constituiu-se apenas em um dos componentes da policy community que defendia a reforma. Por um lado, a elite de reformadores atraiu lideranças populares e sindicais para que esses se envolvessem nos fóruns públicos de representação política que eram criados. Por outro, tomaram parte ativa no desenho de políticas e de estratégias que impulsionassem o processo reformista. Ao invés de tomar decisões através de um processo informal de consulta a uma sociedade civil debilmente organizada, eles promoveram a normalização de mecanismos de representação de interesses coletivos no setor saúde, tendo como pressuposto a existência de movimentos popular e sindical, suficientemente organizados para garantir a continuidade e a consistência desse processo de representação.

Embora, durante os anos oitenta, tenha havido intensa mobilização da sociedade civil no Brasil, a estrutura organizativa daí resultante varia de acordo com a região do país, com o estado e com as características 
demográficas, econômicas e políticas das cidades. A força de instituições políticas e dos movimentos popular e sindical em cidades grandes, por exemplo, tende a tornar viável a participação de grupos de pressão, determinando o tipo de envolvimento que os usuários teriam nos conselhos e nas conferências de saúde (Carvalho e outros, 1992; Cortes, 1995; IBAM e outros, 1991; IBAM e outros, 1993; L'Abbate, 1990; Martes, 1990). Clientelismo e paternalismo ainda são características marcantes nas relações entre governo e grupos de interesse no Brasil, especialmente nas pequenas cidades e nas áreas rurais menos industrializadas do país. Embora a existência desses fóruns possa colaborar para a consolidação de formas mais democráticas de representação de interesses, eles têm seu funcionamento limitado e condicionado pela realidade concreta das instituições e da cultura política dos municípios brasileiros. Mesmo levando em conta tais restrições, nos níveis federal, estadual e em municípios onde os movimentos popular e sindical são mais organizados, tem havido envolvimento constante de representantes dos usuários nos espaços públicos dos conseIhos e das conferências de saúde (Carvalheiro e outros, 1992; Cortes, 2000; Vargas e outros, 1985).

Não só as afirmações de Grindle e Thomas sobre a fraqueza da sociedade civil e a informalidade do processo de representação de interesses na América Latina são incompletas, as de U galde também o são. Ele (1985, p.43) afirmou que, na América Latina, as experiências de participação inspiradas pelos princípios dos cuidados de saúde teriam contribuído para aumentar a exploração do pobre através da utilização de seu trabalho gratuito. Elas teriam contribuído para a sua descaracterização cultural, ao mesmo tempo em que acentuavam a violência política pela exclusão ou supressão de líderes e pela destruição de organizações de base. O s conseIhos e as conferências de saúde não são "experiências de participação". Eles são fóruns institucionalizados, similares aos encontrados na Inglaterra, Itália, Estados U nidos ou Canadá (Cortes, 1996 (b)). No entanto, uma fonte de inspiração para a sua criação foi a proposta de participação comuni- 
tária preconizada pelos cuidados primários de saúde. As afirmações de U galde podem ser consideradas como parcialmente adequadas para caracterizar experiências participatórias que tiveram lugar, durante as duas últimas décadas, em projetos de extensão de cobertura de cuidados de saúde, no interior e em áreas urbanas pobres do Brasil. Não se aplicam, porém, aos conselhos e as conferências de saúde.

São inadequadas, portanto, as afirmações de Grindle e Thomas e de U galde, que subestimam a possibilidade de participação de setores populares em processos reformistas ou em ações inspiradas pela estratégia de atenção primária à saúde na América Latina e, por conseguinte, no Brasil. As circunstâncias que cercam e as características que conformaram o processo de criação dos conselhos e das conferências de saúde e sua consolidação legal e política demonstram essa inadequação.

\section{Antecendentes históricos da criação de fóruns participatórios na área de saúde}

No Brasil, até a década de setenta, existiram mecanismos participatórios institucionalizados unicamente na área previdenciária. A previdência social oferecia benefícios e serviços aos trabalhadores inseridos no mercado formal de trabalho, que pagavam contribuições. Entre esses serviços estava a assistência ambulatorial e hospitalar individual. Durante o regime militar, que se estendeu de 1964 a 1985, houve a supressão de qualquer tipo de participação de representantes de trabalhadores contribuintes em órgãos decisórios ou consultivos da previdência social. Entretanto, a partir de 1974 foram tomadas iniciativas no sentido de estimular o envolvimento da "comunidade" no setor saúde. As primeiras medidas nesse sentido, no entanto, foram implementadas na área de saúde pública, cujos serviços destinavam-se àquela parcela da população excluída do acesso a serviços de saúde previdenciários. 
Desde o início da previdência social brasileira, através da criação, em 1923, das Caixas de Aposentadorias e Pensões, havia eleição de representantes dos trabalhadores contribuintes em órgãos decisórios dessas instituições (Oliveira e Teixeira, 1986, p.22). As caixas eram organizadas por empresas, como sociedades civis, nas quais a única participação estatal dava-se por meio da normatização de seu funcionamento feita através de lei federal, aprovada pelo Congresso Nacional. Elas atendiam marítimos e ferroviários e suas famílias, oferecendo aposentadorias, pensões, pecúlios e assistência ambulatorial e hospitalar em caso de cirurgia (O liveira e Teixeira, 1986, p.22). A participação de representantes de trabalhadores ocorria em seu principal órgão diretivo, o qual era composto por três membros designados pela empresa e dois do corpo de empregados, eleitos diretamente (Oliveira e Teixeira, 1986, p.32-3).

O s Institutos de Aposentadorias e Pensões, criados a partir de 1933, também tinham mecanismos participatórios; careciam, no entanto, de autonomia em relação ao Estado. Os institutos previdenciários eram autarquias vinculadas ao Ministério do Trabalho, que abrangiam categorias nacionais de trabalhadores urbanos, tais como marítimos, estivadores, industriários, bancários, comerciários, servidores públicos federais (Malloy, 1977, p.46-7). O utras categorias de trabalhadores urbanos - domésticos, autônomos, servidores públicos municipais - e os da área rural não foram atingidos pelo sistema. 0 governo federal interferia na escolha dos representantes dos trabalhadores que tomavam parte em órgãos diretivos dos institutos (O liveira e Teixeira, 1986, p.118-131). Depois de 1945, a democratização política e o crescimento econômico industrial favoreceram 0 fortalecimento do movimento sindical, aumentando sua influência na escolha dos dirigentes dos institutos e, principalmente, na indicação dos representantes dos empregados que deveriam tomar parte nas instâncias colegiadas dos institutos previdenciários.

0 regime autoritário militar, a partir de 1964, promoveu a centralização das instituições políticas e estimulou o crescimento da provisão priva- 
da de bens e serviços. A reforma fiscal, os Atos Institucionais, a Constituição outorgada, de 1967, e as emendas constitucionais, de 1969, concentravam poder político, competências e recursos financeiros nas mãos da União. Ao lado da centralização de poder, constituía-se um padrão autoritário de administração pública, que defendia o planejamento e a gestão baseados em decisões técnicas e a supressão de canais abertos à manifestação pública de interesses seccionais. Nesse contexto, foram fechados os mecanismos de participação dos trabalhadores em órgãos decisórios e consultivos da previdência social.

A partir de 1974, no entanto, o governo passa a demonstrar maior preocupação com a promoção de políticas que levassem a expansão da provisão de ações e serviços de saúde. Ao mesmo tempo em que diminuía o ritmo do crescimento econômico, que caracterizara o chamado "milagre econômico brasileiro", o regime militar sofria o enfraquecimento de suas bases sociais de apoio. 0 novo presidente militar, empossado naquele ano, propunha a gradual liberalização política e um novo discurso social, consubstanciado no II Plano Nacional de Desenvolvimento (Paim, 1989, p.19). O plano propugnava a implementação de novas estratégias de planejamento social e a racionalização do sistema de saúde. De acordo com novas diretrizes, foram criados os planos de extensão de cobertura, planejados e executados verticalmente pelo governo federal e impostos aos estados e municípios. As ações mais inovadoras foram aquelas que visaram estender a cobertura a parcelas da população até então excluídas de qualquer tipo de acesso a serviços de saúde. A proposta mais ambiciosa foi a tentativa, em 1979, de implementar um Programa $\mathrm{Na}$ cional de Serviços Básicos de Saúde (PREVSAUDE). Embora a iniciativa não tenha tido sucesso, pela primeira vez discutia-se, nacionalmente, uma proposta que incorporava, entre seus elementos centrais, a noção de participação comunitária no setor (Paim, 1989, p.20).

O utro conjunto de iniciativas que visavam modificar os serviços de saúde pública tinha como protagonistas algumas secretarias municipais de saúde. No final da década de setenta, em municípios de pequeno e médio 
porte, em geral governados por opositores do regime militar, secretarias municipais de saúde implementaram políticas inspiradas pelos princípios dos cuidados primários de saúde. Além de oferecerem cuidados básicos para populações pobres, tinham como objetivo envolver usuários em decisões tomadas nos serviços de saúde municipais. 0 grau desse envolvimento variou caso a caso, mas difundia-se, nessas localidades, a idéia de participação na área de saúde. Saliente-se que muitos profissionais de saúde participaram intensamente dessas experiências.

Até o início dos anos oitenta, o sistema brasileiro de saúde era dividido entre os subsetores de saúde previdenciária e de saúde pública, ambos atuando paralelamente, carecendo de integração no planejamento e nas ações. O subsetor previdenciário detinha a maior parte dos recursos financeiros. Ele oferecia serviços de saúde ambulatoriais e hospitalares, acessíveis aos trabalhadores contribuintes, através de unidades próprias e, crescentemente, através de prestadores contratados. A crise econômica e os custos crescentes com a provisão de assistência à saúde fortaleciam as propostas de políticos, de administradores e de líderes dos movimentos popular e sindical, visando reorganizar o sistema para torná-lo universal, descentralizado e melhor integrado. A reorganização implicaria na transferência de poder político e de recursos financeiros do subsetor previdenciário para o de saúde pública e da esfera federal para as administrações estaduais e municipais. A democratização política, o fortalecimento dos níveis sub-nacionais de governo (Souza, 1994, p.588-589) e as recomendações das agências internacionais, motivaram a implementação de políticas e a constituição de regramento legal que veio a universalizar o acesso, a integrar e a descentralizar o sistema público de saúde brasileiro. Para os que defendiam a redução do tamanho do estado e da proporção de gastos com proteção social pública, o objetivo principal era o corte de custos. Em contraste, aqueles que defendiam a democratização do acesso a serviços e a ampliação do controle estatal sobre os serviços financiados com recursos públicos, ressaltavam a importância de estimular a participação dos usuários. 
Ao longo da década de setenta e na primeira metade dos anos oitenta, buscando liberalizar o regime, uma vez que a crise econômica havia reduzido sua legitimidade política, o governo militar tomou medidas procurando constituir novos canais de representação de interesses. Visava-se legitimar o regime autoritário e ampliar as bases sociais de apoio através da implementação de políticas para aliviar pobreza e de expansão de cobertura previdenciária. Simultaneamente as relações corporativistas entre os interesses empresariais e a tecnocracia do setor público (Cardoso, 1975, p.181-6) eram criticadas até mesmo pela burguesia, insatisfeita com o declínio nas atividades econômicas. Foram restabelecidas ou criadas formas democráticas de representação e expressão política, tais como eleições para cargos do poder executivo, liberdade de imprensa, de associação e de organização partidária. Projetos e programas governamentais previam a criação de comissões ou conselhos que deveriam ter entre seus componentes representantes da sociedade civil. U ma característica marcante da reforma do sistema de saúde brasileiro, durante os anos oitenta, foi a criação desse tipo de mecanismo participatório.

\section{Criação de Fóruns Participatórios no contexto da reforma do sistema brasileiro de saúde}

$\mathrm{Na}$ década de oitenta, dois programas do governo federal e um conjunto de provisões legais podem ser considerados como os fundamentos institucionais da reforma do sistema brasileiro de saúde. Eles foram os Programas das Ações Integradas de Saúde, de 1984, dos Sistemas Unificados Descentralizados de Saúde, de 1987, a Constituição Federal, de 1988, e as Leis Federais 8.080 e 8.142, de 1990.

O Programa das Ações Integradas de Saúde, criado em 1984, fazia parte da estratégia do regime militar para reduzir os custos do sistema previdenciário, que haviam crescido durante os anos setenta. Ele estabelecia que a previdência social transferiria recursos financeiros para governos esta- 
duais e municipais que optassem por tomar parte no programa. 0 principal objetivo era melhorar a rede de serviços espalhada nos três níveis de governo, retendo a demanda por cuidados ambulatoriais e hospitalares financiados pela previdência social. Para facilitar a integração das ações dos provedores públicos de serviços, foram criadas comissões interinstitucionais nos níveis federal, estadual, regional, municipal e local da administração pública. Essas comissões foram denominadas, respectivamente, Comissão Interministerial de Planejamento e Coordenação (CIPLAN), Comissão Interinstitucional de Saúde (CIS), Comissão Regional Interinstitucional de Saúde (CRIS), Comissão Interinstitucional M unicipal de Saúde (CIM S) e Comissão Local Interinstitucional de Saúde (CLIS). As três primeiras comissões eram compostas por representantes dos prestadores de serviços e do governo, ao contrário das duas últimas que previam o envolvimento de entidades comunitárias, sindicais, gremiais, representativas da população local (Brasil. Ministério da Previdência e Assistência Social e outros, 1984, p.8). À exceção das comissões regionais, as demais foram se institucionalizando como importantes fóruns de debate no setor. Além de auxiliarem a integração interinstitucional, os novos fóruns foram gradativamente se transformando em canais de representação política dentro da organização estatal.

As comissões municipais deveriam decidir sobre a alocação de recursos financeiros previdenciários transferidos para as municipalidades e monitorar 0 modo como eles eram gastos. O s cuidados de saúde oferecidos diretamente pelas esferas federal, estadual e municipal, financiados com recursos dos orçamentos desses níveis da administração pública, não estavam incluídos nas agendas de discussão das comissões. Particularmente nas capitais e nas cidades de grande porte, com movimentos social e sindical fortes, grupos de interesse - tais como associações de moradores, sindicatos, organizações que representavam profissionais e trabalhadores de saúde - pressionavam pela ampliação da pauta de discussões. Eles viam no empowerment desses fóruns a abertura de possibilidades inéditas de participação no processo de decisão política setorial (Carvalheiro e outros, 1992, p.116-27). 
Em agosto de 1987, o governo federal iniciou o Programa dos Sistemas Unificados Descentralizados de Saúde, com objetivo de universalizar o acesso a cuidados de saúde e, ao mesmo tempo, racionalizar custos e 0 uso de recursos, através da unificação dos serviços de saúde dos subsetores previdenciário e de saúde pública. A proposta era de integração dos serviços de saúde da previdência à rede descentralizada de unidades hospitalares e, principalmente, ambulatoriais do subsetor de saúde pública, pertencentes aos governos estaduais e municipais. 0 s governos estaduais assinavam convênios de adesão através dos quais a previdência social transferia aos estados recursos financeiros e funções de gerenciamento dos serviços próprios e de contratação de prestadores privados. 0 programa também estabelecia que as municipalidades que aderissem ao convênio estadual, poderiam receber recursos e assumir o gerenciamento de unidades ambulatoriais e hospitalares anteriormente federais, e também das estaduais, que se encontrassem em sua área territorial. 0 programa propunha integração, virtualmente extinguindo o envolvimento direto da previdência social na provisão de cuidados de saúde e na compra de serviços. Havendo municipalização, as secretarias municipais de saúde se tornariam os gestores dos serviços existentes em seus territórios, exceção feita àqueles que, devido ao seu nível maior de complexidade, fossem referências para populações de mais de um município.

O s reformadores do sistema brasileiro de saúde consideravam como uma questão de princípio que a sociedade civil tivesse controle sobre 0 sistema. Ao mesmo tempo, os grupos de interesse mobilizados através de fóruns de participação poderiam auxiliar para expandir os apoios políticos ao processo de reforma. 0 programa abriu as comissões interinstitucionais estaduais de saúde à participação popular e reforçou o papel de representantes da sociedade civil nas comissões municipais e locais. 0 Programa habilitou as comissões municipais a tomar parte nas decisões sobre serviços contratados, uma vez que houvesse ocorrido a municipalização. 
A Constituição Federal do Brasil, promulgada em 1988 (Brasil, 1988), e as Leis 8.080 e 8.142 aprovadas pelo Congresso Nacional, em 1990 (Brasil. Congresso, 1990 (a); Brasil. Congresso, 1990 (b)), foram influenciadas pela policy community de reformadores do sistema brasileiro de saúde em aliança com organizações que representavam os interesses dos usuários. A estratégia geral era construir um sistema universal e único de saúde, financiado com recursos da seguridade social - criada pela nova Constituição - e dos orçamentos federal, estaduais e municipais. A maior parte da provisão direta e da regulação dos serviços financiados com recursos públicos ficaria a cargo dos municípios. As esferas federal e estadual assumiam a responsabilidade pelo monitoramento e avaliação do sistema e pela provisão de serviços de maior complexidade que se constituíssem em referência para populações de mais de um município. Embora por lei a atenção à saúde tenha se tornado obrigação municipal, até meados da década de noventa, particularmente nas cidades de grande porte, a municipalização dependeu do sucesso de negociações complexas, muitas vezes conflituosas, entre autoridades de saúde municipais e estaduais. Debatia-se sobre como e quando os serviços passariam para a esfera administrativa municipal, quais deles seriam repassados e, principalmente, qual o acordo financeiro que viabilizaria ao município assumir os novos encargos.

A Lei 8.142/90 (Brasil. Congresso, 1990 (b)) ampliou ainda mais as possibilidades de envolvimento de usuários no processo de decisão setorial em comparação com o que havia sido proposto pelos programas anteriores. Deveriam ser constituídos conselhos de saúde permanentes, nos níveis federal, estadual e municipal da administração pública, os quais deveriam ser compostos por representantes do governo, de prestadores de saúde, de profissionais de saúde e de usuários. Metade do conselho seria formada por representantes dos usuários e a outra metade por conselheiros oriundos dos demais segmentos sociais. Um dos requisitos, para que as 
secretarias estaduais e municipais se habilitassem a receber recursos financeiros federais, era a existência de conselhos organizados de acordo com as determinações legais ${ }^{1}$. Esses fóruns deveriam participar do estabelecimento de estratégias, decidir sobre a alocação de recursos financeiros e monitorar a implementação de políticas. Como a provisão de serviços de saúde se tornara principalmente uma obrigação municipal, uma vez ocorrido o processo de municipalização, os conselhos municipais poderiam vir a ter controle sobre os cuidados de saúde, financiados com recursos públicos, dentro do território da cidade.

M esmo considerando as dificuldades e as resistências para tornar realidade as propostas políticas e as determinações legais, até meados do ano 2000, 97,04\% dos municípios do país (5.343 em 5.506) haviam municipalizado a rede ambulatorial básica pública e os serviços de vigilância em saúde (epidemiológica e sanitária) existentes em seus territórios. No entanto, apenas $8,97 \%$ (494 em 5.506) haviam passado a ter controle também sobre todos os serviços financiados com recursos públicos ambulatoriais, hospitalares, terapêuticos ou de apoio diagnóstico - inclusive aqueles contratados de prestadores privados (Brasil. Ministério da Saúde, 2000). As organizações que representam interesses de usuários têm renovado esforços para aumentar sua influência nos conselhos de saúde nacionais, estaduais e municipais. Elas parecem reconhecer que, no novo desenho institucional, foi aberta a possibilidade para que os usuários participem do processo de decisão política setorial.

A mesma lei criava também as conferências de saúde, nos três níveis da administração pública, as quais deveriam ter a mesma composição dos conselhos e ocorrer a cada quatro anos. Elas deveriam avaliar a situação de saúde e propor diretrizes para a formulação da política de saúde nos níveis correspondentes. Embora tenham sido realizadas oito conferências nacionais de saúde anteriormente a 1990, apenas a última delas - a 8a Conferência Nacional de Saúde - teve participação popular marcante, possivelmente

1 Para receber recursos financeiros federais, as secretarias de saúde estaduais e municipais deveriam ter: (1) fundo de saúde, (2) conselho de saúde, (3) plano de saúde, (4) relatório de gestão, (5) considerável contrapartida de recursos financeiros oriundos dos orçamentos próprios destinados à função saúde, (6) plano de carreira cargos e salários. 
por ter sido realizada em 1986, no contexto da democratização política, dos conflitos e negociações que precederam o processo constitucional e de intensa discussão sobre os rumos da reforma do sistema de saúde. A partir de então realizaram-se duas conferência nacionais - em 1993 e em 1996 precedidas pela organização de cerca de cinco mil conferências municipais e estaduais em todos os estados da federação. A mobilização que elas provocaram pode ser atestada pelo processo de escolha de delegados, cercado, muitas vezes, de disputas acirradas entre diferentes entidades buscando garantir a presença de seus representantes no evento. Há indicações de que tem sido respeitada a exigência legal de paridade entre representantes de usuários, vis-a-vis demais segmentos sociais (Cortes, 2000).

A legislação criou os conselhos e as conferências nos níveis federal, estadual e municipal da administração pública, mas eles não foram instituídos a partir de um vazio institucional. $\mathrm{Na}$ maior parte dos casos, os conseIhos originaram-se da adaptação das comissões interinstitucionais existentes, desde a segunda metade da década de oitenta, às novas exigências legais. A realização de conferências era tradição no setor, desde o início do século; a principal diferença introduzida foi o regramento em relação à periodicidade e ao envolvimento de representantes da sociedade civil.

Esses fóruns vêm modificando seu caráter dentro de um sistema de saúde em processo de mudança. Desde 1984, quando as autoridades de saúde federais deram prioridade à integração interinstituicional e à descentralização, através do Programa das Ações Integradas de Saúde, os fóruns permanentes - inicialmente comissões depois conselhos - além de facilitarem a integração, estavam se tornando um espaço para o qual eram canalizadas demandas e conciliados os interesses de prestadores, de trabaIhadores e profissionais de saúde, de gestores públicos e de representantes do movimento popular e sindical (Cortes, 1995).

Estudos têm demonstrado, entretanto, que, desde o início dos anos noventa, os representantes da categoria médica e dos prestadores privados de serviços têm se retirado dos fóruns participatórios, marcadamente dos conse- 
Ihos municipais (Cortes, 1995). Líderes desses setores argumentam que os conselhos são hostis aos médicos e aos prestadores privados de serviços. Eles estariam subrepresentados nesses fóruns considerando sua importância no setor (Entrevista 16, 1992; Entrevista 21, 1992). Evidentemente tais grupos de interesse não foram excluídos do processo de decisão política setorial. Sua influência é exercida diretamente sobre os gestores, através de canais formais e informais de exercício de pressão política. Exemplos de canais formais seriam o legislativo, a mídia ou a apresentação pública de demandas aos gestores. O s canais informais se constituiriam, principalmente, através de administradores públicos identificados com as demandas de médicos e prestadores privados de serviços de saúde. A identificação tem muitas vezes caráter corporativo, pois os gestores públicos freqüentemente são médicos ou proprietários de hospitais ou de equipamentos de apoio diagnóstico ou terapêutico. Salientese que a legislação proíbe que proprietários de serviços exerçam posições de chefia no sistema público de saúde. No entanto, muitas vezes o médico, dono de hospital ou de outros equipamentos, abandona formalmente a direção daquela organização apenas durante o período em que exerce a função de gestor público, permanecendo sua identificação com os interesses da corporação médica e dos prestadores privados de serviços.

Diferentemente do que ocorria na segunda metade dos anos oitenta, os conselhos e as conferências de saúde, na década de noventa, parecem ter deixado de ser o local principal de negociações e de mediação de interesses setoriais. Esses fóruns, entretanto, assumiram dois papéis institucionais fundamentais. Em primeiro lugar, nos conselhos e durante as conferências de saúde, articulavam-se às forças sociais favoráveis ao aprofundamento do processo de reforma do sistema. Em segundo lugar, a medida que que o processo de municipalização se consolidava, eles passaram a ser o locus onde os representantes dos usuários - marcadamente dos moradores das regiões mais pobres das cidades - apresentavam suas demandas aos gestores públicos. A mediação entre projetos conflitantes para o setor parece estar ocorrendo, preferencialmente, nos gabinetes dos gestores públicos de saúde. 
O s projetos em conflito são basicamente dois. De um lado, estão os reformistas do sistema brasileiro de saúde, que defendem a expansão da provisão pública de serviços, o aumento do controle estatal sobre o mercado de serviços de saúde e 0 acesso universal de todos os cidadãos ao sistema. A policy community de reformistas é liderada por gestores públicos, principalmente municipais, interessados em aprofundar a autonomia dos municípios e obter mais verbas para custear a rede de serviços sob sua responsabilidade. É liderada também por ativistas dos movimentos popular e sindical e por dirigentes de associações e sindicatos de profissionais e de trabalhadores de saúde interessados na expansão do acesso a serviços universais e em garantir a ampliação da provisão pública de cuidados de saúde. Especialmente nas capitais dos estados e nas cidades de grande porte, eles se articulam nos conselhos municipais e durante as conferências, apoiados pela legitimidade política e legal desses fóruns, confrontando opositores, pressionando prefeitos, governadores e o governo federal para exigir, por exemplo, a destinação de mais verbas para o setor saúde.

De outro lado, estão os liberais que defendem a provisão privada de serviços para aqueles que podem pagar e a oferta de serviços financiados com recursos públicos apenas para as camadas mais pobres da população. Os principais líderes da resistência ao processo de reforma são os empresários médiCos, a Federação Brasileira de Hospitais (FBH) e suas ramificações estaduais, a Associação Brasileira de Medicina de Grupo (ABRAMGE) que representa as health maintenance organizations ${ }^{2}$ brasileiras, o Conselho Federal de M edicina e suas ramificações estaduais, além de alguns sindicatos médicos. Para eles, os conselhos e as conferências de saúde são território inimigo.

Mesmo levando em conta que conselhos e conferências exerçam de modo limitado o papel de mediadores de interesses no setor, a novidade é a formação gradual de um novo tipo de relacionamento na área da saúde no Brasil, no qual os interesses dos setores populares, tradicionalmente excluídos do processo de decisão política, vêm sendo representados formal e publicamente (Carvalheiro e outros, 1992; Vargas e outros, 1985; Cortes, 1998).

2 Empresas que oferecem serviços ambulatoriais de saúde contratadas por empresas para oferecer assistência a seus trabaIhadores (Cordeiro?). 


\section{Determinantes da participação dos usuários}

Constatou-se acima que os conselhos e as conferências de saúde têm sido um espaço público dentro do qual os interesses dos setores populares são representados e no qual os representantes desses setores têm participado do processo de tomada de decisão política que lá ocorre. Examina-se agora os determinantes da participação dos representantes dos usuários nestes fóruns. A sistematização da literatura sobre o tema (Cortes, 1995; Jacobi, 1993; Lee e Mills, 1985; Marmor, 1983; Martes, 1990; Vargas e outros, 1985) apontou os seguintes fatores como os mais influentes sobre esse processo participatório: (1) mudanças recentes na estrutura institucional do sistema brasileiro de saúde, (2) organização dos movimentos popular e sindical, (3) relacionamento entre profissionais de saúde pública e lideranças populares e sindicais, (4) posições das autoridades federais, estaduais e municipais de saúde em relação a participação, (5) dinâmica de funcionamento dos fóruns. Duas observações preliminares devem ser feitas para esclarecer a natureza desses determinantes. Em primeiro lugar, na realidade, todos eles se afetam mutuamente, compondo as partes de um todo integrado e conflituoso. Em segundo lugar, os dois primeiros fatores são os mais decisivos. Ou seja, os fóruns não existiriam não fosse a estrutura institucional que os criou e somente haverá participação se houver organização da sociedade civil. Em certos casos podem ocorrer resistências das autoridades municipais de saúde em relação à participação dos usuários e mesmo assim ela ocorrer em função da pressão dos movimentos sociais (Cortes, 1995, p.135-137).

As transformações recentes na estrutura institucional do sistema brasileiro de saúde podem ser consideradas como o fator mais influente na determinação do processo participatório que ocorre nos conselhos e conferências de saúde. Essas mudanças formam o conjunto de programas e disposições legais, já mencionado, implementados durante a década de oitenta, acrescidos das normas operacionais do M inistério da Saúde, edita- 
das em 1993 e 1996, as quais normatizaram e estimularam o processo de municipalização. Esse conjunto ofereceu as bases políticas e legais para que o sistema brasileiro de saúde se tornasse: (1) mais integrado, através da unificação do subsetor de saúde pública (Ministério da Saúde, Secretarias Estaduais e Municipais de Saúde) com o subsetor de saúde previdenciária (serviços próprios e contratados); (2) mais descentralizado, repassando funções e transferindo equipamentos e recursos financeiros para as secretarias estaduais de saúde, e mais tarde, para os municípios; e (3) universalizado, formalmente oferecendo cobertura de cuidados de saúde a toda a população brasileira. Nesse contexto, desde o início dos anos noventa tem crescido a importância dos conselhos e das conferências de saúde, tanto como locus de articulação das forças políticas favoráveis à reforma do sistema de saúde, quanto como canal formal e aberto de encaminhamento de demandas e proposições dos representantes dos setores populares, que são os usuários regulares dos serviços financiados com recursos públicos.

No entanto, a força dos movimentos popular e sindical é que determinará a ocorrência ou não de participação de representantes legítimos e autônomos dos setores populares nesses fóruns. M ais que isso, o padrão de organização dos movimentos sociais influencia o modo como os usuários se envolvem nas atividades dos conselhos e das conferências. Se o padrão de organização for mais centralizado, a tendência é que os representantes dos usuários se envolvam diretamente nas atividades dos conselhos nacional, estaduais e municipais das cidades grandes. Se o padrão de organização for mais descentralizado, os representantes usuários chegarão a eles através de organizações locais, tais como os conselhos locais de saúde, clubes de mães, associações comunitárias ou de moradores, entre outras (Cortes, 1995). A importância dos movimentos sociais urbanos, especialmente nas cidades maiores, é decisiva porque os representantes do movimento sindical nos conselhos - excluídos os que representam trabalhadores de saúde - têm sido minoria. Isso possivelmente se explica pelo fato de os setores de trabalhadores mais mobilizados 
serem aqueles cujos membros já dispõem de seguros ou planos de saúde especiais, não contando unicamente com o sistema público para atender a suas necessidades. Em cidades pequenas, onde os sindicatos de trabalhadores rurais são fortes, eles se constituem na principal base de sustentação para a participação continuada de seus representantes junto aos conselhos municipais (Vargas e outros, 1985). Saliente-se que esses trabalhadores também dispõem apenas do sistema público para suprir suas necessidades de atenção à saúde. As possibilidades de envolvimento autônomo dos representantes de usuários nas conferências municipais, que escolhem os delegados que participarão das etapas estaduais e federal, dependem da consistência do envolvimento nos conselhos municipais. 0 caráter episódico das conferências as transforma em momento culminante de um longo processo gestado ao longo dos quatro anos que antecedem a realização de cada uma delas.

U m terceiro fator que tem estimulado o envolvimento de usuários nos conselhos e nas conferências é a ação combinada dos reformadores do sistema brasileiro de saúde com a dos ativistas dos movimentos sociais urbano, rural e sindical (Cortes, 1995; Martes, 1990; Vargas e outros, 1985). A elite de reformadores tem atuado também junto ao executivo e legislativo, visando a introdução de modificações político-institucionais que viabilizem a participação dos usuários. Esses reformadores defendem a participação, porque eles acreditam na democratização do processo de decisão política estatal. Além disso, a aliança com os movimentos sociais oferece suporte político no enfrentamento de resistências dos grupos de interesse contrários às reformas e no confronto dentro do governo com outras áreas políticas, que competem com a de saúde pela obtenção de recursos escassos.

0 interesse de setores dos movimentos social ou sindical em reivindicar a melhoria do acesso e da qualidade dos serviços de saúde não se traduz, automaticamente, na canalização de demandas para os conselhos e conferências de saúde. A elite de reformadores estimulou o envolvimento de lideranças populares e sindicais nos contatos que eles estabeleceram, enquanto profissionais de saúde pública em unidades ambulatoriais, loca- 
lizadas em áreas urbanas pobres ou em regiões que concentravam trabaIhadores rurais. Eles também favoreceram 0 envolvimento dos usuários nesses fóruns quando ocupavam cargos como gestores federais, estaduais e municipais de saúde. Em algumas áreas urbanas, como no Setor 4, em Porto Alegre (Cortes, 1995), na Zona Leste de São Paulo (Jacobi, 1993; Martes, 1990) ou em Ronda Alta no Rio Grande do Sul (Vargas e outros, 1985), a já existente intensa mobilização popular em torno das questões de saúde foi canalizada para esses fóruns. Em outras áreas onde também existia a predominância de populações pobres, mas a questão saúde não era tratada como prioridade pelos movimentos sociais locais, o encorajamento dos profissionais de saúde pública foi decisivo para 0 envolvimento de lideranças populares com as questões de saúde. Sem ele a mobilização para o encaminhamento de soluções para os problemas de saúde teria provavelmente sido menos intensa e a ação política desses segmentos da população não teria convergido, necessariamente, para os fóruns participatórios da área de saúde. A contrapartida para as lideranças dos movimentos sociais urbanos e do movimento sindical era o aumento de sua influência política sobre o processo de tomada de decisões no setor saúde. Através do acesso direto às autoridades de saúde nesses fóruns, eles exerciam pressão pela melhoria da qualidade dos serviços de saúde oferecidos às populações pobres que eles representam. Ao mesmo tempo, eles reforçavam a sua posição de liderança dentro das suas organizações.

Um quarto fator que contribui para a participação dos usuários nos conselhos e nas conferências de saúde, é a posição das autoridades municipais, estaduais e federais de saúde sobre a participação de usuários. A posição das autoridades de saúde pode ser considerada como decisiva, pois muitas vezes eles dirigem o conselho e a organização da conferência. Mesmo quando não é esse o caso, como gestores, eles influenciam diretamente: (1) na formação da agenda de discussão, (2) no funcionamento geral do fórum, (3) na possibilidade de cumprir as decisões ali tomadas e (4) na possibilidade de pressionar os demais gestores e os prestadores de 
serviços de saúde para o cumprimento das decisões. Saliente-se que, na medida em que avançar o processo de descentralização, mais importante se tornará o papel do gestor municipal no conjunto do sistema e sobre as possibilidades de haver participação dos usuários, enquanto que a influência das autoridades federais e estaduais declinará.

U m quinto determinante da participação é a dinâmica de funcionamento dos fóruns. Ela está ligada à forma de coordenação do fórum e à postura do gestor em relação à participação. Ela poderia explicar mudanças de curto prazo no envolvimento dos usuários (Cortes, 1995). Nos conselhos a sobrecarga de discussões detalhadas sobre despesas a serem realizadas, por exemplo, pode levar ao esvaziamento de reuniões de conselho (Cortes, 2000). A divisão clara de competências entre comissões técnicas, jurídicas ou similares pode ajudar a evitar esse tipo de problema, se a intenção for evitá-lo, caso contrário pode se constituir numa estratégia para diminuir o poder deliberativo do conselho. Da mesma forma, ao limitar as questões que entram na pauta de discussão, o gestor pode fazer como que assuntos importantes para a políticas de saúde municipal, permaneçam como não-questões (Bachrach e Baratz, 1963). Estando fora da agenda de discussões, as decisões relativas a eles serão tomadas em gabinetes, longe, portanto, do escrutínio público.

\section{Considerações finais}

No Brasil, a partir dos anos oitenta, alguns setores da administração pública, marcadamente o de saúde, têm sido permeáveis à representação de interesses daqueles setores sociais tradicionalmente alijados do processo político. É certo que essa novidade convive com a permanência de arranjos políticos elitistas e de práticas clientelísticas e paternalistas que dificultam a generalização dessa nova permeabilidade. A crise econômica dos anos oitenta minou as bases do pacto autoritário que excluía as representações de trabalhadores e de outros setores sociais populares dos centros de decisão política. A liberalização política possibilitou a manifestação pública de uma 
sociedade civil que demonstrou capacidade de organização autônoma, pelo menos nos principais centros urbanos e nas áreas rurais que concentravam os mais ativos sindicatos de trabalhadores rurais. A consolidação dos conseIhos e das conferências de saúde, como espaços para os quais foram canalizadas as demandas dos movimentos popular e sindical, teve sucesso onde formou-se uma "policy community" composta por uma elite de reformadores do sistema brasileiro de saúde em aliança com lideranças dos movimentos popular e sindical. A aliança que se solidificou nos conselhos de saúde tem se manifestado nas conferências de saúde. Assim, as afirmações de Grindle e Thomas e de U galde, que consideraram pouco provável a constituição de mecanismos formais e públicos de representação dos interesses das classes populares na América Latina, não retratam integralmente, nem valorizam, a novidade que constituem os conselhos e as conferências de saúde para a vida político-institucional do país.

No entanto, a demora no processo de municipalização dos serviços de saúde, em muitos estados, tem limitado as possibilidades de extensão da agenda de discussões dos conselhos municipais. Enquanto o gerenciamento dos serviços de saúde nas cidades não estiver sob controle municipal, o poder de decisão política dos conselhos e das conferências municipais, dentro do processo decisório geral do setor, tenderá a ser limitado. Em outras palavras, sem a municipalização o aumento do controle dos usuários sobre esses fóruns não significará ampliação do controle sobre a gestão dos serviços de saúde da cidade. A municipalização apenas da atenção básica, como tem ocorrido na esmagadora maioria dos municípios brasileiros, faz com que o gestor municipal e, por conseguinte, os conselhos tenham influência limitada sobre o processo de decisão setorial.

Ressalve-se, ainda, que a assistência à saúde, no Brasil, está dividida entre os cuidados disponíveis para aqueles que dispõem de convênios especiais ou que podem comprar serviços privados diretamente e aquela assistência acessível aos que somente podem recorrer ao serviços financiados com recursos públicos. Isso tem levado a que principalmente as po- 
pulações mais pobres e os portadores de doenças crônicas - em menor proporção - se interessem em influir no processo de decisão política que tem lugar nos fóruns participatórios.

Mesmo considerando tais limitações, tem se constatado que, em alguns casos e em certas conjunturas, os conselhos e as conferências de saúde têm propiciado a representação pública dos interesses dos setores populares e os representantes desses setores têm participado no processo de tomada de decisão política que lá ocorre. O s principais determinantes da participação dos representantes dos usuários nos conselhos e conferências têm sido: (1) mudanças no sistema brasileiro de saúde, (2) características dos movimentos popular e sindical, (3) relacionamento entre profissionais de saúde pública e lideranças populares e sindicais, (4) posições dos gestores federais, estaduais e, principalmente, municipais em relação à participação, e (5) dinâmica de funcionamento do fórum. Como foi visto, esses determinantes estão profundamente relacionados e se afetam mutuamente, embora os dois primeiros possam ser destacados como os mais decisivos.

$\mathrm{N}$ ão se pode afirmar que a reforma do sistema brasileiro melhorou a qualidade dos cuidados oferecidos e que tornou os serviços mais acessíveis ou se ela, ao contrário, intensificou iniquidades territoriais e sociais que já existiam. Não há dúvida, no entanto, que ela criou, no nível municipal de governo, um fórum participativo que tem contribuído para a democratização do processo de tomada de decisões no setor saúde. Maior participação de usuários não garante a redução das iniqüidades na promoção de cuidados de saúde para a população. No entanto, a consolidação de fóruns participativos pode auxiliar para a democratização das instituições brasileiras, dando voz a setores tradicionalmente excluídos de representação direta no sistema político. Através deles, seus representantes podem influir na decisão sobre o destino de recursos públicos no setor saúde, podem obter informações, fiscalizar a qualidade dos serviços prestados e podem influenciar na formulação de políticas que favoreçam os setores sociais que eles representam. 
Sociologias, Porto Alegre, ano 4, № 7, jan/jun 2002, p. 18-49

\section{Referências bibliográficas}

ALM EIDA, Maria Hermínia Tavares de. 0 sindicalismo brasileiro entre a conservação e a mudança. In: Sociedade e política no Brasil pós-64. Ed. Bernardo Sorj and Maria Hermínia Tavares de Almeida. São Paulo: Brasiliense, 1984, p.191-214.

ARNSTEIN, Sherry R. A ladder of citizen participation. Journal of American Institute Planners 35 (3), 1969, p.216-24.

BACH RACH , Peter e BARATZ, M orton S. Decisions and non-decision: an analytical framework. American Political Science Review 57, 1963, p.632-42.

BAIERLE, Sérgio Gregório. U m novo princípio ético-político: Prática social e sujeito nos movimentos populares urbanos em Porto Alegre nos anos 80. M.S. diss., Universidade Estadual de Campinas, 1992.

Brasil. Constituição da República Federativa do Brasil de 05 de 0 utubro de 1988.

Brasil. Congresso. Lei 8.080 de 19 de Setembro de 1990 - Dispõe sobre as condições para a promoção, proteção, e recuperação da saúde, a organização e o funcionamento dos serviços correspondentes e da outras providências. 1990 (a).

Brasil. Congresso. Lei 8.142 de 28 de Dezembro de 1990 - Dispõe sobre a participação da comunidade na gestão do Sistema Ú nico de Saúde - SU S e sobre as transferências intergovernamentais de recursos financeiros na área de saúde e dá outras providências. 1990 (b).

Brasil. Ministério da Previdência e Assistência Social, Ministério da Saúde, Ministério da Educação e Cultura, Governos Estaduais, e Governos M unicipais. Ações Integradas de Saúde. Porto Alegre: Secretaria da Saúde e do M eio Ambiente. Fotocopiado. 1984.

Brasil. Ministério da Saúde. 2000. Situação atual do processo de habilitação. www.saude.gov.br/descentralização.

CARDOSO, Fernando Henrique. Autoritarismo e democratização. Rio de Janeiro: Paz e Terra, 1975. 
CARVALHEIRO, José R.; DONATO, Ausonia F.; HEIMANN, Luiza S.; IBANHES, Lauro C.; LOBO, Elza F. e PESSOTO, Umberto C. O município e a saúde. São Paulo: Hucitec, 1992.

CARVALH O, Guido Ivan de e Santos, Lenir. Sistema Ú nico de Saúde: Comentários à Lei O rgânica de Saúde (Leis 8.080/90 e 8142/90). São Paulo: Hucitec, 1992.

CO RTES, Soraya M. V. U ser participation and reform of the Brazilian Health System: The case of Porto Alegre. Londres: London School of Economics and Political Science, Department os Social Policy and Administration, Dissertação de D outorado, 1995.

CO RTES, Soraya M . V. Fóruns participatóriosna área de saúde: Teorias do estado, participantes e modalidades de participação. Revista Saúde em Debate 49/50, 1996 (a), p.73-79.

CO RTES, Soraya M. V. As origens da idéia de participação na área de saúde. Revista Saúde em Debate 51, 1996 (b), p.30-37.

CORTES, Soraya M. V. Perfil dos delegados da 10a Conferência Nacional de Saúde. www.datasus.gov.br / links / Conferência Nacional de Saúde on line, 2000.

Entrevista 16. Entrevistado por Soraya Cortes, 19 de 0 utubro. Transcrito. Arquivos do NIPESC/IFCH/U FRGS. Porto Alegre, 1992.

Entrevista 21. Entrevistado por Soraya Cortes, 14 de 0 utubro. Transcrito. Arquivos do NIPESC/IFCH/U FRGS. Porto Alegre, 1992.

GRIN DLE, M erilee S. e THO MAS, John W. Public choices and policy change: The political economy of reform in developing countries. London: The Jonhs H opkins University Press, 1991.

GRZYBO W SKI, Cândido. Caminhos e descaminhos dos movimentos sociais no campo. Petrópolis: Vozes, 1987.

HALL, Anthony L. Developing Amazonia: Deforestation and social conflict in Brazil's Carajás programme. M anchester: M anchester University Press, 1990. 
Sociologias, Porto Alegre, ano 4, no 7, jan/jun 2002, p. 18-49

HAM, Chris J. Community health council participation in NHS planning system. Social Policy and Administration 14 (3), 1980, p.221-31.

IBAM - Instituto Brasileiro de Administração Social, Ministério da Saúde, e Fundação Nacional de Saúde. Perfil dos municípios na área de saúde. Ministério da Saúde, Fundação N acional de Saúde, IBAM . Fotocopiado. 1991.

IBAM - Instituto Brasileiro de Administração Social, NESCO/PR - Núcleo de Estudos em Saúde Coletiva, IMS/UERJ - Instituto de Medicina Social, N ESCO/U FM G Núcleo de Pesquisas em Saúde Coletiva e Nutrição, N ESS/U FBa - Núcleo de Estudos em Serviços de Saúde, NESC/FIO CRUZ - Núcleo de Estudos em Saúde Coletiva, e N ESCO/UFCE - Núcleo de Estudos em Saúde Coletiva. Avaliação do funcionamento dos conselhos estaduais e municipais de saúde: Relatório executivo. M inistério da Saúde, Conselho Nacional de Saúde. Fotocopiado. 1993.

JACO BI, Pedro. M ovimentos sociais e políticas públicas. São Paulo: Cortez, 1993.

JORDAN, Grant, e RICHARDSO N, J. J. The British policy style or the logic of negotiation? In: Policy styles in western Europe. Ed. J. J. Richardson. London: Allen and Unwin, 1982, p.81-98.

KECK, Margaret E. The new unionism in the Brazilian tradition. In: Democratising Brazil: Problems of transition and consolidation. Ed. Alfred Stepan. 0 xford: 0 xford University Press, 1989, p.252-96.

L'ABBATE, Solange. $O$ direito à saúde: $D$ a reivindicação à realização. Projetos de política de saúde em Campinas. U niversidade de São Paulo, Dissertação de Doutorado, 1990.

LEE, Kenneth e MILLS, Anne. Policy-making and planning in the health sector. London: Croom Helm, 1985.

MALLOY, James M. Social security policy and working class in twentieth-century Brazil. Journal of Interamerican Studies and W orld Affairs 19 (1), 1977, p.35-59.

M ARM OR, Theodore R. Political analysis and American medical care. New York: Cambridge U niversity Press, 1983. 
MARTES, Ana C. B. A institucionalização dos movimentos de reivindicação urbana - As secretarias de saúde e a participação popular (1979-1989). M.S. diss., U niversidade de São Paulo, 1990.

M ELO, M arcus A. C. Anatomia do fracasso: Intermediação de interesses e a reforma das políticas sociais na Nova República. Dados-Revista de Ciências Sociais 36 (1), 1993, p.119-163.

M O ISÉS, José A. Cidadania e participação - Ensaio sobre o plebiscito, o referendo e a iniciativa popular na nova Constituição. São Paulo: M arco Zero, 1990.

O LIVEIRA, Jaime A. A. e TEIXEIRA, Sonia M. F. (Im)previdência social: 60 anos de história da previdência social no Brasil. Petrópolis: Vozes-Abrasco, 1986.

PAIM , Jair Nilson S. As políticas de saúde e a conjuntura atual. Espaço para a Saúde 1 (M arço), 1989, p.18-24.

PAU L, Samuel. Community participation in development projects - The World Bank experiences. W ashington: W orld Bank, 1987.

SO UZA, Celina. Political and financial decentralisation in democratic Brazil. Local government studies 29 (4), 1994, p.588-609.

U GALDE, Antonio. Ideological dimensions of community participation in Latin America health programs. Social Science an M edicine 1, 1985, p.41-53.

VARGAS, Gilberto P.; Da SILVA, G.; MORLIM, J. P.; CASTRO, M. S. M. de; ESPINATO, N. A.; MERG, R. D.; BO NFADA, S. T. e ANDREZEJEW SKI, T. Participação dos trabalhadores rurais nos serviços de saúde de Ronda Alta. Escola de Saúde Pública de Porto Alegre. Trabalho de Conclusão do Curso de Saúde Pública, 1985.

WALT, Gill. Health policy: An introduction to process and power. London: Zed Books, 1994.

WEFFO RT, Francisco C. N otas sobre o desenvolvimento político do Brasil. São Paulo: Seminário da UN ESP. Fotocopiado, 1988. 
Sociologias, Porto Alegre, ano 4, o 7, jan/jun 2002, p. 18-49

\section{Resumo}

0 artigo discute o trabalho de autores que afirmam existir dificuldades em criar canais participatórios nos países em desenvolvimento em geral, e na América Latina em particular, devido à fraqueza de suas instituições políticas e sociedades civis. $\mathrm{Na}$ área da saúde, as iniciativas para promover a participação teriam resultado em fracasso. Argumenta-se, em contrapartida, que a experiência brasileira, com os conselhos e as conferências de saúde, não confirma integralmente tais afirmações. 0 artigo também examina as origens históricas, a criação e o papel político-institucional desses fóruns, no contexto da reforma do sistema brasileiro de saúde. Ao final, o artigo analisa os determinantes do sucesso de um processo participatório em conselhos e conferências de saúde.

Palavras-chave: participação dosusuários, conselhosde saúde, conferênciasdesaúde. 